\title{
Autoregulation of a segmentation gene in Drosophila: combinatorial interaction of the even-skipped homeo box protein with a distal enhancer element
}

\author{
Jin Jiang, ${ }^{1}$ Timothy Hoey, ${ }^{2}$ and Michael Levine ${ }^{1}$ \\ Department of Biological Sciences, Fairchild Center, Columbia University, New York, New York 10027 USA
}

\begin{abstract}
Autoregulation has been implicated in the expression of many patterning genes in Drosophila, but the molecular details of this process are largely unknown. In the case of the segmentation gene even-skipped (eve), autoregulation is important for the specification of sharp stripes of gene expression at the onset of gastrulation. Here, we use a combination of DNA binding and P-transformation assays to characterize the cisand trans-acting factors responsible for autoregulation. We show that eve autoregulation is mediated, at least in part, by a 100-bp minimal autoregulatory sequence (MAS) located $\sim 5 \mathrm{~kb}$ upstream from the eve transcription start site. Multimerization of a 200-bp DNA fragment that encompasses the MAS drives optimal autoregulatory activity, comparable to that obtained with the native distal enhancer element located between -5.9 and $-5.2 \mathrm{~kb}$. The MAS contains two eve protein-binding sites, as well as binding sites for two nuclear factors present in early embryos. Directed mutagenesis of these binding sites suggests that both the $e v e$ protein and nuclear factors are essential for autoregulation. These results provide evidence that the $e v e$ protein acts combinatorially with other transcription factors to enhance its own expression.
\end{abstract}

[Key Words: Autoregulation; Drosophila; even-skipped; homeo box protein; segmentation]

Received September 24, 1990; revised version accepted December 11, 1990.

Drosophila segmentation is governed by a hierarchy of interactions among a set of $\sim 25$ regulatory genes that are active in the early embryo (Nüsslein-Volhard and Wieschaus 1980; for review, see Akam 1987; Ingham 1988). One of these is the pair-rule gene even-skipped (eve), which encodes a homeo box protein that is critical for initiating the metameric organization of the embryo (Harding et al. 1986; Macdonald et al. 1986; Frasch et al. 1987). eve is unique among the pair-rule genes in that weak (or hypomorphic) alleles delete alternating segments, while strong (or null) alleles result in the complete loss of segment boundaries within middle body regions of mutant embryos (Nüsslein-Volhard et al. 1985). Genetic studies have identified a total of four target genes that are either directly or indirectly regulated by eve, including the segment polarity genes engrailed (en) and wingless $(w g)$, as well as the pair-rule genes fushi tarazu (ftz) and eve itself (Harding et al. 1986; Macdonald et al. 1986; Frasch et al. 1988; Ingham et al. 1988). Previous studies have established that eve encodes a sequence-specific transcription factor (Hoey and Levine 1988; Biggin and Tiian 1989; Han et al. 1989), which is likely to interact directly with one or more of the genet-

Present addresses: 'Biology Department, Bonner Hall, UCSD, La Jolla, California 92093-0346 USA, ${ }^{2}$ Department of Molecular and Cell Biology, University of California, Berkeley, California 94724 USA. ically defined target genes of eve (Harding et al. 1986; Macdonald et al. 1986; Frasch et al. 1988).

To understand how the eve protein functions as a transcription factor in vivo, we have focused on the process of eve autoregulation. eve is initially expressed in a series of seven broad, symmetric stripes along the length of precellular embryos. During a period of only $30 \mathrm{~min}$, these stripes are refined so that each includes two to three cells and show clear anterior-posterior polarity by the onset of gastrulation. A sharp on/off border forms at the anterior edge of each stripe, with peak levels of eve protein in the anterior-most cell. The formation of these asymmetric eve stripes is the earliest manifestation of segment polarity, with the anterior border of each stripe defining parasegment boundaries by activating en (Lawrence et al. 1987). The refinement of the eve stripes depends on $e v e^{+}$gene activity. In $e v e^{-}$embryos, the stripes fail to sharpen and there is a premature loss of eve expression (Frasch et al. 1988; Lawrence and Johnston 1989). Genetic studies suggest that eve autoregulation is complex and depends on the activities of at least two other pair-rule genes, hairy $(h)$ and runt (run) (Frasch and Levine 1987; Frasch et al. 1988; Goto et al. 1989|. eve and $h$ are positive regulators, while run exerts a strong negative effect on eve expression.

Promoter fusion studies have shown that the initiation of individual eve stripes depends on separate cis- 
regulatory elements, which are controlled (directly or indirectly) by the products of the gap genes (Goto et al. 1989; Harding et al. 1989; Stanojevic et al. 1989|. In contrast, the refinement of all seven stripes depends on a common cis-regulatory element that is located in a far distal region of the eve promoter, which maps between -5.9 and $-5.2 \mathrm{~kb}$ upstream from the transcription start site. This distal element can drive seven stripes of expression from a heterologous promoter in P-transformed embryos (Goto et al. 1989; Harding et al. 1989). Such expression was observed only in $e^{+} e^{+}$embryos and disappeared in $e^{-} e^{-}$mutants. These observations prompted the proposal that the distal sequences correspond to an autoregulatory element, which mediates the refinement of the eve stripes by the direct interaction of the eve protein. Further dissection of the distal autoregulatory element led to the identification of a 200-bp sequence that is sufficient to drive seven stripes of expression in response to $\mathrm{eve}^{+}$activity (Harding et al. 1989). However, this expression was found to be reduced substantially as compared with that obtained from the full-length autoregulatory element.

Here we show that a normal level of late eve expression can be achieved by multimerizing this 200-bp sequence, suggesting that autoregulation involves some type of cooperative mechanism. We have further narrowed the limits of the minimal autoregulatory sequence (MAS) to a 100-bp region of the eve promoter, located between -5.35 and $-5.25 \mathrm{~kb}$. The 100-bp MAS is sufficient to produce stripes of expression in P-transformed embryos when multimerized and attached to an hsp 70-lacZ fusion gene. In vitro-binding assays have revealed two clusters of eve protein-binding sites within the MAS. Base substitutions that disrupt these binding sites cause a corresponding reduction in autoregulatory activity in vivo. These results suggest that eve autoregulation involves the direct interaction of the eve protein with its own promoter, via the binding sites identified within the MAS. In addition, we have characterized two additional nuclear factor-binding sites within the MAS. Point mutations that abolish the in vitro-binding activity of either site also cause severe reductions in autoregulatory activity. We propose that the eve protein acts combinatorially with these two nuclear factors to activate its own expression. One of the factors may correspond to tramtrack $\{t|k|$, a zinc finger protein that is expressed in early embryos (Harrison and Travers 1990; D. Reed and J.L. Manley, pers. comm.).

\section{Results}

The cis-regulatory elements identified within the eve promoter are summarized in Figure 1, on the basis of studies done by Harding et al. (1989) and Goto et al. (1989). Individual eve stripes are initiated by separate cis-regulatory elements, while the maintenance and refinement of the stripes in older embryos depends on an autoregulatory element located between -5.9 and -5.2 $\mathrm{kb}$. A 1.6-kb or 900-bp DNA fragment spanning this element was shown to induce striped expression of a het-

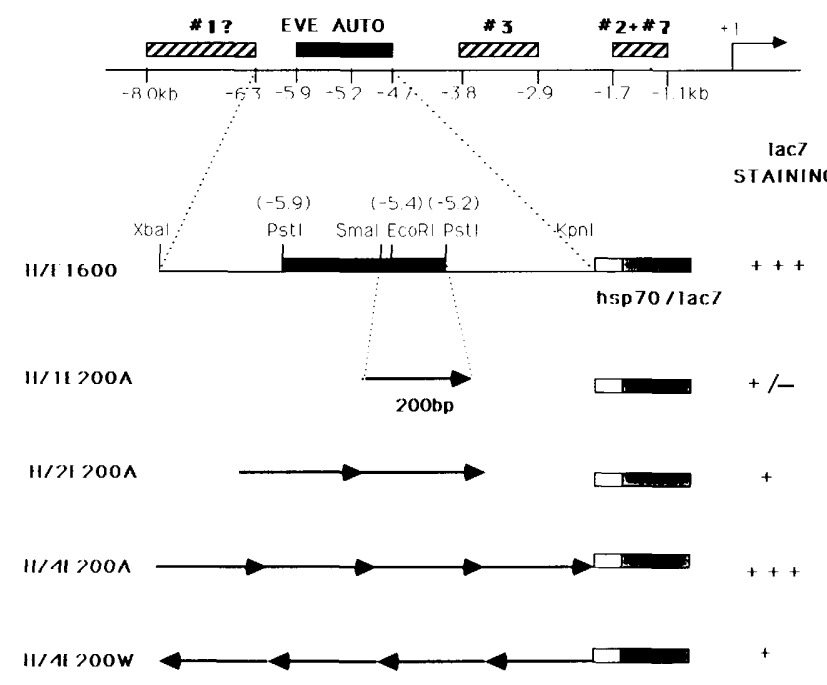

Figure 1. Summary of eve promoter elements and multimerization of autoregulatory sequences. (Top line) A map of the eve promoter and the limits of four different cis-regulatory elements identified in previous studies (Goto et al. 1989; Harding et al. 1989). The hatched boxes indicate stripe initiation elements, with the numbers indicating eve expression stripes. Autoregulatory sequences were mapped to a distal region, between -5.9 and $-5.2 \mathrm{~kb}$ upstream from the transcription start site $(+1)$. A 1.6-kb DNA fragment that spans this region /from -6.3 to $-4.7 \mathrm{~kb}$ ) was shown to induce strong expression $1+++1$ of the heterologous $h s p 70$ minimal promoter, when attached to the $\operatorname{lac} Z$ reporter gene and introduced into embryos via P-element transformation. A 200-bp SmaI-Pst I fragment (from about -5.4 to $-5.2 \mathrm{~kb} /$ within the autoregulatory element was shown to induce only very weak $(+1-)$ expression from the $h s p 70$ promoter in P-element transformants. Multiple copies of this fragment were placed upstream of the $h s p 70-1 a c Z$ gene fusion, and their activities were examined in P-transformed embryos by monitoring the expression of the $\operatorname{lac} Z$ reporter using an anti- $\beta$-galactosidase antibody. The horizontal arrows correspond to the 200-bp Smal-Pst fragment and their orientation within the P-expression vector relative to the $h s p 70$ minimal promoter. The rectangles correspond to the $h s p 70-l a c Z$ gene fusion, with the stippled region indicating the limits of the bacterial $\operatorname{lac} Z$ gene and the open region representing the $h s p 70$ promoter. The activities obtained with a two-copy promoter fusion (H22E200A) were stronger than that obtained with just one copy. A four-copy promoter (HZ4E200A) containing the fragments in the correct orientation gave very intense expression $(+++)$, whereas much weaker expression $(+)$ was observed when they were placed in opposite orientation (HZ4E200W).

erologous $h s p 70$ promoter when expressed in embryos via P-element transformation (Goto et al. 1989; Harding et al. 1989). Strong expression of the lacZ reporter gene was observed in wild-type embryos but disappears in $e v e^{-}$embryos. Smaller fragments from the autoregulatory element were used in the P-transformation assays in an effort to identify the minimal sequences that can mediate autoregulation. The smallest piece of DNA that was found to work is $200 \mathrm{bp}$ in length and maps between -5.4 and $-5.2 \mathrm{~kb}$ (Harding et al. 1989). However, expression with this fragment is significantly weaker than that obtained with the full-length autoregulatory ele- 
ment. Other DNA fragments in the distal region completely failed to mediate autoregulation, including a 370bp fragment located between -5.9 and $-5.5 \mathrm{~kb}$.

\section{Multimers of the 200-bp fragment restore full autoregulatory activity}

It is possible that the eve autoregulatory element contains mutliple copies of a functionally equivalent sequence. To test this possibility we inserted tandem copies of the 200-bp fragment into the HZ50 expression vector (see Fig. 1). HZ50 is a P-transformation vector that contains the minimal $h s p 70$ promoter attached to the lacZ-coding sequence (Hiromi and Gehring 1987). Initially, we compared the activities of promoters containing $1 \times, 2 \times$, and $4 \times$ copies of the 200-bp autoregulatory fragment. These fusion genes were introduced into the germ line via $P$ transformation, and their relative activities were determined by analyzing transformed embryos with anti- $\beta$-galactosidase antibodies. The results of these experiments are shown in Figure 2.

Fusion genes containing two tandem copies of the 200bp fragment (Fig. 2B) consistently showed much more intense reporter gene expression than that obtained with just one copy of the fragment (Fig. 2, cf. A with B). The one-copy promoter (HZ1E200A) drives weak and even sporadic expression of the lac $Z$ reporter. Expression is primarily restricted to dorsal-lateral epidermis, and over half of the transformed lines show no expression at all. In contrast, two copies of the fragment (HZ2E200A) resulted in consistently strong expression in all five transformed lines that were tested. Moreover, expression was found to include both the mesoderm and ectoderm. The heterologous promoter containing four tandem copies in the normal orientation (HZ4E200A) showed intense lacZ expression (Fig. 2C), even stronger than the staining obtained with the full-length autoregulatory element (Fig. 2D).

The demonstration that multimers of the 200-bp fragment cause a dramatic increase in expression suggests that the authentic autoregulatory element is composed of multiple copies of a functionally similar sequence (see Discussion). Surprisingly, four copies of the 200-bp fragment in opposite orientation (HZ4E200W) give much weaker expression (Fig. 2E) than the same promoter containing the fragments in the correct orientation (Fig. 2D). This orientation dependence might indicate the occurrence of complicated interactions between enhancerbinding proteins and the basal transcription machinery.

\section{Factor binding sites in the eve autoregulatory element}

To determine whether the eve protein might act directly on the autoregulatory element we performed footprint assays using a full-length eve protein made in bacteria (Hoey and Levine 1988). The 200-bp autoregulatory DNA fragment was end-labeled with ${ }^{32} \mathrm{P}$, incubated with increasing amounts of eve protein, and digested with DNase I (Fig. 3A). Two regions of protection were identified, called EVE-P (proximal) and EVE-D (distal). The eve protein appears to bind with somewhat higher affin- ity to EVE-P than EVE-D (see Fig. 3A, lane 4). Each region contains both high- and low-affinity binding sites. Comparative footprint assays indicate that these sites have lower affinities for the eve protein than the A-T-rich binding sites identified in previous studies (data not shown). Inspection of the EVE-P and EVE-D sequences does not reveal extensive homology with previously identified eve-binding sites (Hoey and Levine 1988; Hoey et al. 1988), except that they both possess an AT-rich core (Fig. 4A). Nonetheless, we believe that the EVE-D and EVE-P regions are significant since they contain at least four tightly clustered eve-binding sites within a span of only $80 \mathrm{bp}$. Using the binding conditions described in Materials and methods we estimate an average of no more than one eve site in a random 500-bp DNA fragment.

Genetic studies suggest that eve activates its own expression, yet both cotransfection assays and in vitro transcription experiments have revealed only a repressor activity (Biggin and Tiian 1989; Han et al. 1989). Perhaps eve must interact with "cofactors" to function as an activator. To determine whether the 200-bp autoregulatory fragment might contain binding sites for additional transcription factors we have performed DNA-binding assays using whole nuclear extracts prepared from early Drosophila embryos (Fig. 3B). DNase I footprint assays identified three regions that are protected by increasing amounts of nuclear extract, called DENF1, DENF2, and DENF3 (summarized in Fig. 4A). The DENFl and DENF3 sites share some similarities with the GAGA factor-binding sites (Biggin and Tiian 1988; Soeller et al. 1988), whereas DENF2 contains a TCCT core sequence that is related to factor-binding sites identified in proximal regions of the eve promoter (Read et al. 1990). The zinc finger protein $t$ t $k$ has been shown to bind these proximal sequences (D. Read and J.L. Manley, pers. comm.), and a $t$ tk fusion protein gives a pattern of protection for the DENF2 site that is identical to that obtained with crude nuclear extracts (J. Jiang and D. Read, unpubl.). Thus, it is likely that DENF2 corresponds to $t t k$.

\section{In vivo relevance of factor-binding sites-deletions}

As a first step toward determining the role of factorbinding sites in autoregulation, we analyzed the effects of deletions on the expression of promoter fusions in P-transformed embryos (summarized in Fig. 4). We have shown that two copies of the 200-bp autoregulatory fragment drive strong and consistent expression of $h s p 70$ lacZ gene fusions (Fig. 2B), indicating that this heterologous promoter could be used as a starting point for analyzing the effects of various mutations on autoregulation. For most of the experiments described below, deletions were made within the 200-bp fragment, and two tandem copies of the mutagenized fragment were placed in the HZ50 vector (see Fig. 4B). To generate appropriate deletions, in vitro mutagenesis was done to create four $B c l$ restriction sites along the length of the $200-\mathrm{bp}$ fragment larrows in Fig. 4; for details, see Materials and 


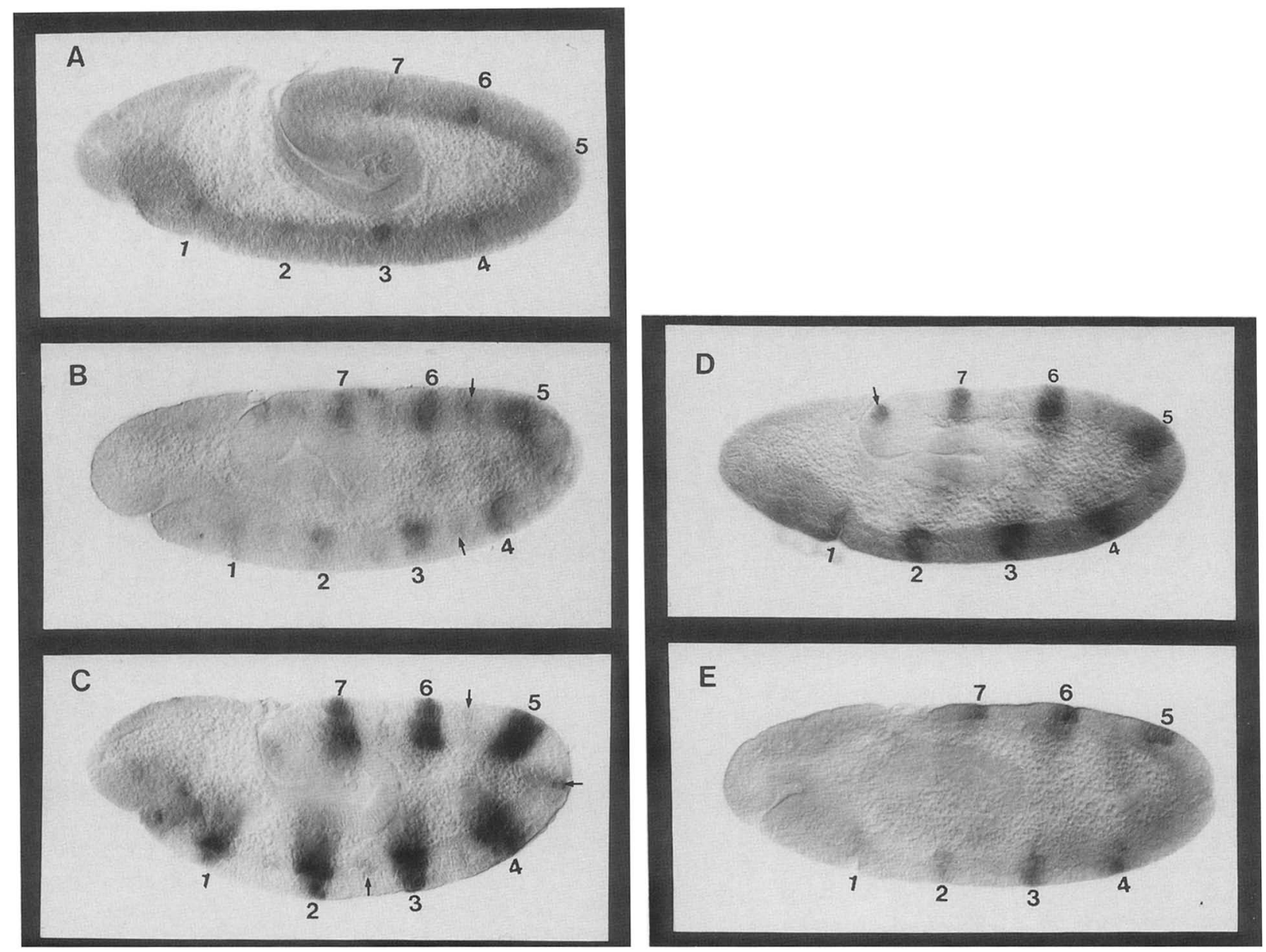

Figure 2. Expression patterns of heterologous promoters in P-transformed embryos. All embryos are oriented so that anterior is to the left and dorsal is up. Embryos were collected from P-transformed lines and stained with anti- $\beta$-galactosidase antibodies. The embryos shown here are $\sim 4-6 \mathrm{hr}$ old and have undergone germ-band elongation. Note the increase in reporter gene expression with promoters containing one, two, and four copies $(A, B$, and $C$, respectively). (A) One copy of the 200-bp fragment (HZ1E200A); (B) two copies of the fragment (HZ2E200A); $(C)$ four copies of the fragment (HZ4E200A); $(D)$ the $1.6-\mathrm{kb}$ fragment that contains the entire autoregulatory region (from -6.3 to $-4.7 \mathrm{~kb}$ ). Note that expression is not quite as strong as that observed for four copies of the 200-bp fragment (cf. with $C) .(E)$ Four copies of the 200-bp fragment in opposite orientation. Note that expression is no stronger than that seen with two copies of the fragment in the correct orientation. The numbers refer to the 7-stripe eve pattern. Arrows indicate weak expression in interstripes. The arrow in $D$ shows expression in the proctodeum, which does not correspond to one of the original eve stripes but is a normal site of eve expression in older embryos (Frasch et al. 1987).

methods|. A 106-bp DNA fragment that includes the region between $B c$ II sites 1 and 4 can mediate autoregulation when six tandem copies are placed in the HZ50 expression vector. The construction of this promoter (HZ6E100) is summarized in Figure 4B, and the staining pattern obtained in P-transformed embryos is shown in Figure 5A. The 106-bp fragment is the minimal sequence found to be active in autoregulation assays, and is referred to as the MAS. Note that the six-copy MAS promoter drives seven weak "spots" of expression (arrows in Fig. 5A), in addition to the seven strong stripes. This pattern is also obtained with the two- and four-copy 200bp promoters (see Fig. 2) and is similar to the endogenous eve pattern that is observed in wild-type embryos at this stage (Frasch et al. 1987).

Sequences located $5^{\prime}$ of the MAS appear to be important for optimal autoregulatory activity. Six copies of the
MAS drive a level of expression comparable to just two copies of the 200-bp autoregulatory fragment (cf. Fig. 2B with Fig. 5A). One interpretation of this finding is that DENF3 is required for optimal expression since the MAS lacks this binding site (see Fig. 4B). However, removal of the DENF3 region from the 200-bp autoregulatory element $\left(2 \mathrm{E} \Delta 3^{\prime}\right.$; Fig. $\left.4 \mathrm{~B}\right)$, has no effect on the levels of expression (Fig. $5 \mathrm{C}$ ). In contrast, deletion of sequences $5^{\prime}$ to $B c l$ site 1 (the $2 \mathrm{E} \Delta 5^{\prime}$ promoter) causes a substantial reduction in expression (Fig. 5B). It is possible that this reduction is due to the loss of factor-binding sites that map in the $5^{\prime}$ region, which were missed in our in vitrobinding assays. A lack of sensitivity of this assay is suggested by our failure to identify the EVE-D and EVE-P regions using whole nuclear extracts.

Internal deletions within the limits of the MAS suggest that some or all of the factor-binding sites are im- 


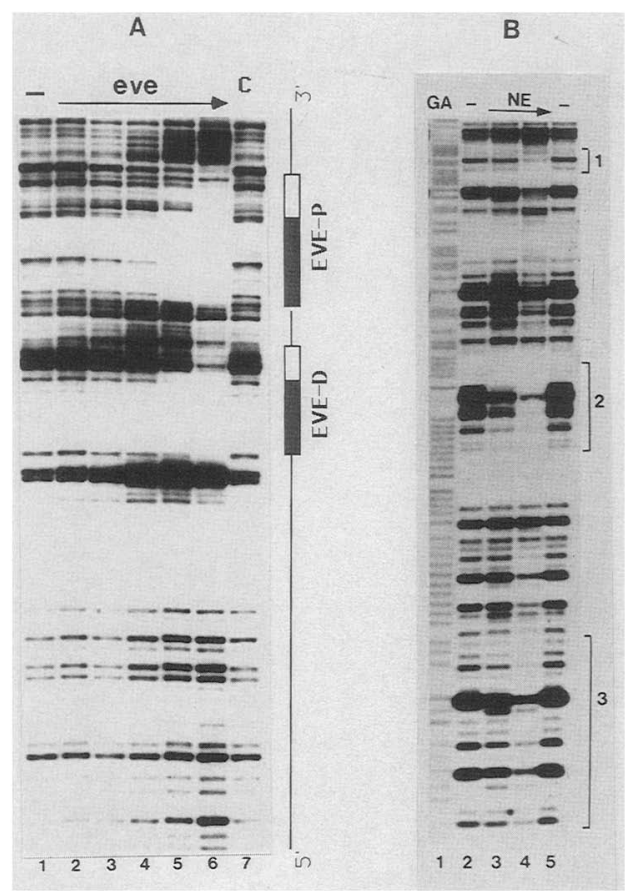

Figure 3. DNA-binding assays with the 200-bp autoregulatory fragment. (A) DNase I footprint assay with eve protein extract from bacteria. The DNA fragment was ${ }^{32} \mathrm{P}$-labeled on the 5 ' end and incubated with various bacterial extracts prior to digestion with DNase I. (Lane 1) no added protein; (lanes 2-6) successive twofold increases in the amount of eve protein extract; (lane 7) total protein extract from bacteria expressing the $\mathrm{T} 7$ vector without eve-coding sequences. The boxes at right of the autoradiogram indicate the regions of protection with increasing amounts of the eve protein, called EVE-D (distal region) and EVE-P (proximal region). The solid regions of the boxes indicate sites of relatively high affinity, whereas the open regions indicate sites with lower affinity. Note that only the high-affinity sites within EVE-D and EVE-P are protected in lane 5, but a twofold increase in the amount of eve protein expands the region of protection into lower affinity sites (lane 6). (B) DNase I footprint assay with a nuclear extract obtained from 4- to l0-hr embryos. The 200-bp autoregulatory fragment was ${ }^{32} \mathrm{P}$-labeled on the noncoding strand, incubated with increasing amounts of nuclear extract (NE). (Lane 1) The G + A sequence of the DNA fragment using the Maxam-Gilbert sequencing method; (lanes 2 and 5) no added protein; (lane 3) addition of $5 \mu \mathrm{g}$ of nuclear extract; (lane 4) addition of $25 \mu \mathrm{g}$ of nuclear extract.

portant for autoregulation. The MAS includes two evebinding sites, as well as DENFl and DENF2 (see Fig. 4B). Deletion of the sequences located between $B c l$ sites 1 and $2(2 E \Delta 12)$ completely abolished the autoregulatory activity of the 200-bp fragment (data not shown). This 44-bp deletion removed the EVE-D- and DENFl-binding sites, suggesting that one or both are essential. The DENF2 site was removed by deleting sequences located between $B c$ II sites 3 and 4 (2E $\Delta 34)$. The $2 E \Delta 34$ promoter gave barely detectable levels of reporter gene expression, indicating that DENF2 is probably important for autoregulation (data not shown). An unexpected result was obtained when the EVE-P site was removed by deleting sequences between $B c l$ I sites 2 and $3(2 \mathrm{E} \Delta 23)$. A heterol- ogous promoter bearing two copies of this deleted fragment appeared to direct a very weak 14-stripe expression pattern (data not shown). To better visualize these stripes, we placed four tandem copies of the fragment (4E $\Delta 23$ ) in the $\mathrm{HZ} 50$ expression vector (Fig. 5D). Each of these stripes is weaker than any of the primary stripes observed with promoters containing four copies of the intact 200-bp autoregulatory fragment (i.e., Fig. 2B). The dramatic alteration in the expression pattern obtained with the $4 \mathrm{E} \Delta 23$ promoter suggests that the EVE-P region might be exerting both a positive and negative effect on the autoregulatory element. It appears to be required for optimal expression of the seven-stripe eve pattern, and it also seems to play a role in suppressing expression in interstripe regions. Alternatively, it is conceivable that the 14-stripe pattern is due to the altered spacing of the remaining factor-binding sites, rather than the loss of EVE-P per se.

\section{In vivo relevance of factor-binding sites-point mutations}

To determine whether the results of the deletion analysis are due to the loss of individual factor-binding sites or altered spacing among the remaining sites, we generated point mutations within EVE-D, EVE-P, DENFl, and DENF2 (see Fig. 6). Base substitutions were made in the context of the 200-bp autoregulatory element. Two copies of the mutagenized fragment were placed in the HZ50 expression vector and used for P-transformation assays. The large sizes of EVE-D and EVE-P suggest that they contain multiple eve protein-binding sites /see summary, Fig. 6). The eve protein recognizes a 10-bp core consensus sequence, while EVE-D and EVE-P are $>20$ and $30 \mathrm{bp}$ in length, respectively. Clustered base substitutions were made in what appear to be the core-binding sites. For EVE-D, we targeted the ATTA sequence since this is a motif found in the vast majority of homeo box recognition sites that have been identified (for review, see Levine and Hoey 1988). A 6-nucleotide substitution was made that converts the sequence ATTATG to GGATCC, thereby completely changing the core ATTA motif (Fig. 6). DNase I footprint assays indicate that these substitutions reduce binding of the eve protein by a factor of at least two- to fourfold and also change the overall pattern of binding (Fig. 7, cf. B with A). Despite this reduced binding, the mutation has no apparent effect on in vivo activity. Reporter gene expression driven by the mutagenized promoter is about as intense as that observed for the wild-type fragment (Fig. 8, cf. E with A). This result suggests that the EVE-D site is not essential for autoregulation, although it appears to function redundantly with the EVE-P region (see below).

Two different clusters of base substitutions were made within the EVE-P region. The first that we tested converts the sequence ATTT to GCTC (Fig. 6), which is nestled in a region of EVE-P that is similar to the mammalian octamer motif (ATTTGCAT; for review, see Levine and Hoey 1988). Footprint assays indicate that these base changes abolish binding of the eve protein to 
Jiang et al.

A

$5.1 \mathrm{~kb}$

CCCGgGCAGIGAGgAAIICCICCGAAAGICGgGICCHCCGIICICCAGCCGAAGA

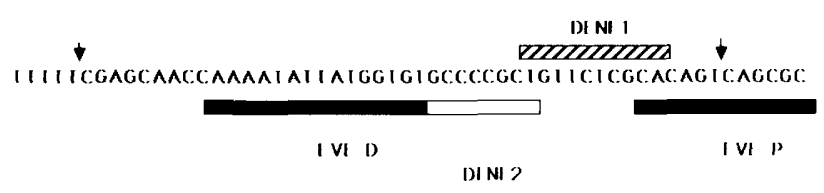

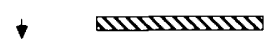

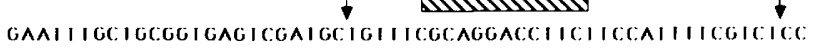

Ganirigciocogionoicionighigin

DI NI 3

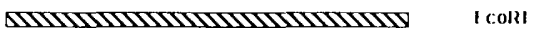

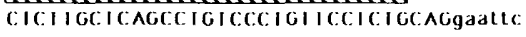

P:stl $\quad 5.2 \mathrm{~kb}$
B

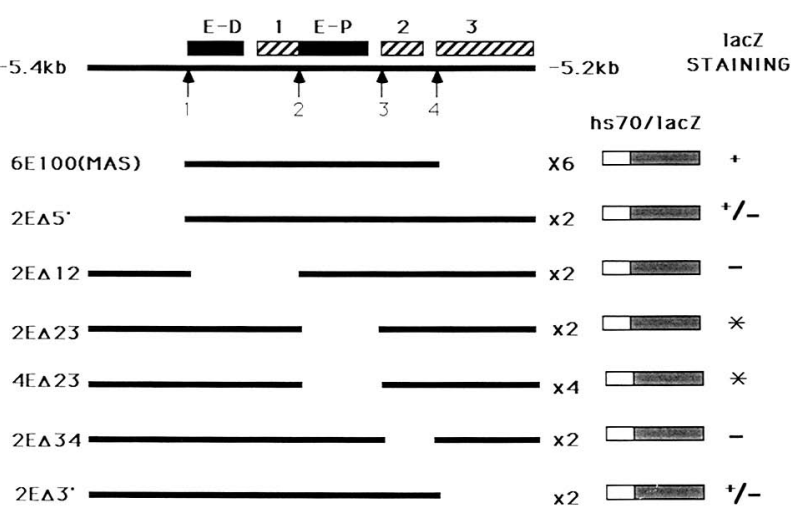

Figure 4. Summary of deletions in the 200-bp autoregulatory fragment. (A) Nucleotide sequence of the 200-bp autoregulatory element. The bars show the limits of factor-binding sites identified within this sequence. The three nuclear factor-binding sites are indicated by hatched bars above the sequence and are called DENF (Drosophila embryo nuclear factor) $1-3$. The two eve-binding sites are indicated by the bars below the sequence. The solid regions show high-affinity sites, while the open regions indicate low-affinity sites. Vertical arrows show the sites where Bcll sites were created by in vitro mutagenesis. $(B)$ The top line corresponds to the autoregulatory element, and the bars represent the two eve-binding sites and three nuclear factor-binding sites. (E-D) EVE-D; (E-P) EVE-P. Numbers correspond to DENF1, etc. A total of four Bcll restriction sites were created in the DNA fragment by in vitro mutagenesis, and their locations are indicated by vertical arrows, 1-4, arrayed from distal to proximal. Note that the BclI sites occur between factor-binding sites. Internal deletions were created within the autoregulatory fragment by digesting templates containing just one or two of the Bcll sites and religating. Each mutagenized template was multimerized and inserted into the HZ50 expression vector. The series of horizontal lines shows the mutagenized fragments, lacking the indicated region of the 200-bp fragment. The numbers to the right indicate the numbers of copies inserted, in tandem, into the HZ50 expression vector. + and - (right) indicate relative activities of the heterologous promoters in P transformants. + $/$ - corresponds to extremely weak staining, which is restricted to dorsal epidermis. The asterisks $(")$ indicate novel expression patterns of 14 stripes, rather than the normal 7 -stripe pattern. The smallest DNA fragment that is able to direct autoregulatory activity extends from Bcll sites 1 to 4 and corresponds to the MAS. Six copies of this 100-bp fragment direct weak expression in P-transformed embryos.

the mutagenized site within EVE-P (Fig. 7C). However, the mutation acts only locally, and binding is not altered in other regions of EVE-P. This mutation has no effect on the seven-stripe eve pattern (Fig. 8C), although the interstripes are more intense than those seen with comparable wild-type promoters (i.e., Fig. 8A). This result is consistent with the deletion analysis, indicating that EVE-P is involved in suppressing interstripe expression. The second mutation made in EVE-P converts the sequence CAGCG to GGATC (Fig. 6; SEP1). This region was selected for mutagenesis since it shares some similarity with the so-called class II eve recognition sequence, which includes the consensus TCAGCACCG (Hoey et al. 1988). The mutation abolishes binding to this site (data not shown) but has no effect on in vivo activity (Fig. $8 \mathrm{~B})$.

The limited effects of the two EVE-P mutations led us to create the double mutant (SEP3; Fig. 6), which knocks out both the TCAGCACCG-like site and the octamerlike element. This mutagenized DNA fragment shows a severe reduction in the binding of eve protein to the EVE$\mathrm{P}$ region (Fig. 7D). Nonetheless, it is quite active in vivo and drives a $l a c Z$ expression pattern similar to the SEP2 mutation (see Fig. $8 \mathrm{C}$ ), whereby interstripe expression is somewhat more intense than normal. This derepression of the interstripes might be due to impaired binding of the homeo box protein $e n$, since $e n^{-}$embryos show a 14-stripe eve pattern that persists during advanced stages when eve is normally off (Harding et al. 1986).

To test the possibility that the EVE-D and EVE-P regions function redundantly, we analyzed the effects of the triple mutant (NE; Fig. 6) on autoregulation. This mutation contains disruptions in the core EVE-D region, as well as in both of the high-affinity EVE-P-binding sites. Promoters containing this mutagenized fragment show a substantial reduction in expression (Fig. $8 \mathrm{~F}$ ) as compared with either the wild-type promoter (Fig. 8A) or promoters containing disruptions in just single sites (Fig. $8 \mathrm{~B}-\mathrm{D}$ ). The embryo shown in Figure $8 \mathrm{~F}$ displays the strongest staining observed for any of the transformed lines, and it is possible that this residual expression is due to the activities of the remaining weak eve-binding sites within the EVE-D and EVE-P regions. The virtual loss of autoregulatory activity suggests that the two evebinding regions identified here play an important role in eve expression and represent bona fide eve regulatory sites.

The effects of mutagenizing the DENF1 and DENF2 sites suggest that they are also essential for autoregulation. Clustered 6-nucleotide substitutions were made in each site. For DENF1, the sequence TGTTCT was converted to GTCGAC (SNF1; Fig. 6), which results in reduced binding to nuclear extracts (see Fig. 7E). This disruption of the DENFl site causes a severe reduction in 


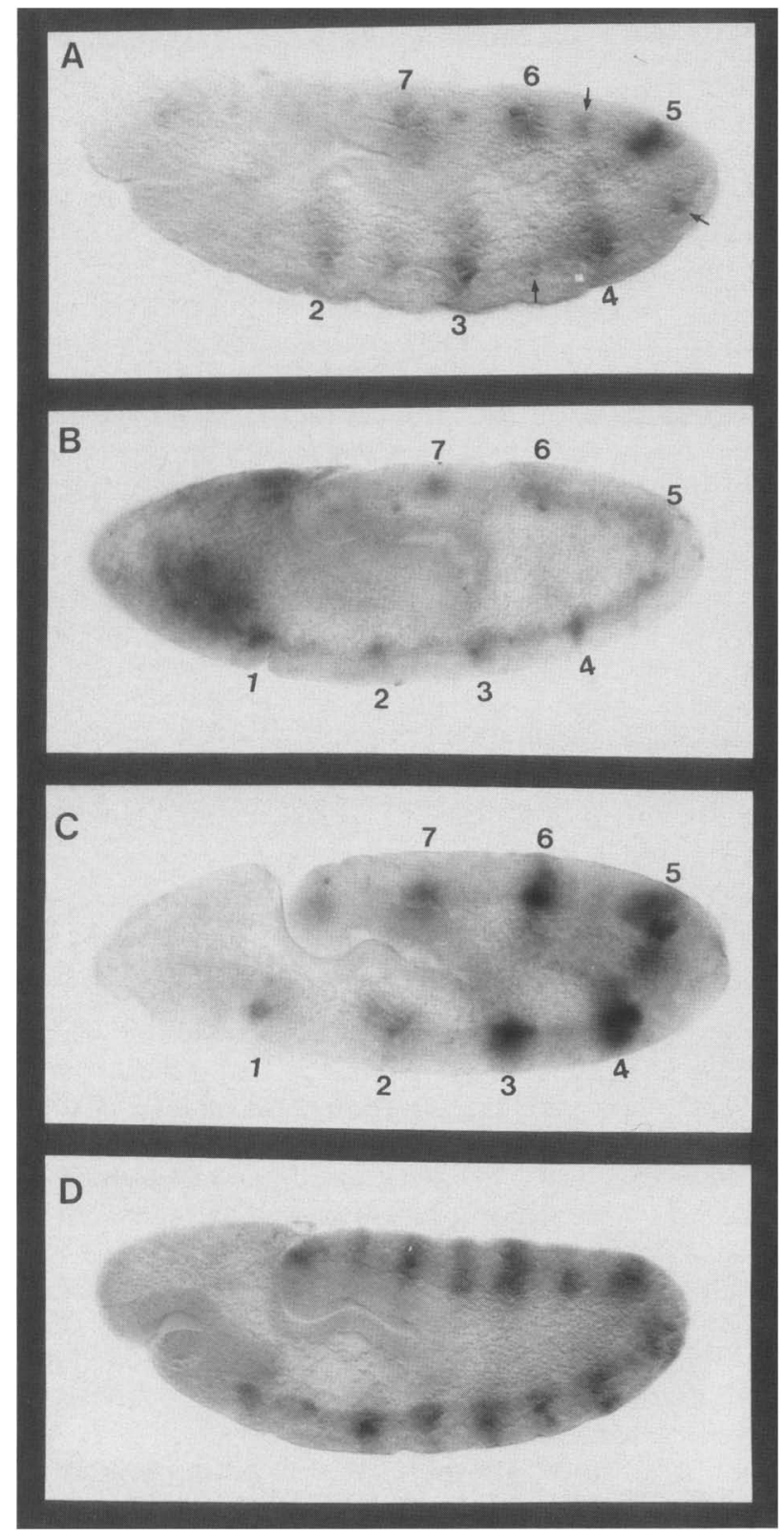

autoregulatory activity (Fig. 8G). Similarly, substitution of the core CAGGAC sequence within DENF2 (SNF2; Fig. 6) nearly abolishes in vitro-binding activity (Fig. 7F) and causes a substantial reduction in autoregulatory activity in vivo (Fig. $8 \mathrm{H}$ ). The near loss of in vivo activity resulting from mutations in the DENF1 and DENF2 sites is not due to altered binding of the eve protein to the EVE-D and EVE-P sites (data not shown). Instead, it would appear that the DENF1 and DENF2 factors act combinatorially with the eve protein to activate transcription.

\section{Discussion}

eve autoregulation is mediated by a distal enhancer element located between -5.9 and $-5.2 \mathrm{~kb}$ upstream from the eve transcription start site. We have shown that mul-
Figure 5. In vivo activities of deleted promoters. Embryos were collected from $P$ transformants containing the expression vectors shown in Fig. 4B. Embryos were stained with anti- $\beta$-galactosidase antibodies and are oriented so that anterior is to the left and dorsal is up. The numbers refer to eve stripes, and the arrows indicate weak expression in interstripe regions. (A) Embryo expressing the HZ6E 100 promoter, which includes six tandem copies of the 106-bp MAS. The pattern and intensity of expression are similar to that observed with two copies of the intact 200-bp fragment (see Fig. 2B). (B) The HZ2E $\Delta 5$ ' promoter. This promoter lacks 60 bp from the $5^{\prime}$ region of the 200-bp fragment, upstream of the BclI 1 site. There is a substantial decline in expression, similar to that observed with just one copy of the intact 200-bp fragment (see Fig. 2A). (C) The HZ2E $\Delta 3^{\prime}$ promoter. This lacks $3^{\prime}$ sequences downstream from $B C I I$ site 4 , and removes the DENF3-binding site. The staining pattern is unaffected and appears quite similar to that obtained with two intact copies of the 200-bp fragment (see Fig. 2B). $(D)$ The $4 \mathrm{E} \Delta 23$ promoter. This contains four tandem copies of a deleted fragment lacking sequences between $B c$ II sites 2 and 3 , which removes the EVE-P region. A 14-stripe pattern is observed instead of the normal 7 -stripe pattern.

timers of a 200-bp DNA fragment from this region function as well as or better than the full-length 700-bp autoregulatory element to activate transcription from a heterologous $h s p 70$ promoter. A 100-bp MAS was identified that contains two eve-binding sites, as well as two binding sites for nuclear factors present in early embryos. Mutations that interfere with the binding of any one of these factors cause a catastrophic loss in expression, which suggests a combinatorial mechanism for eve autoregulation, whereby the eve protein interacts with neighboring nuclear factors to function as a transcriptional activator.

Cooperative interactions among eve autoregulatory elements

Autoregulation has long been thought to play an impor- 

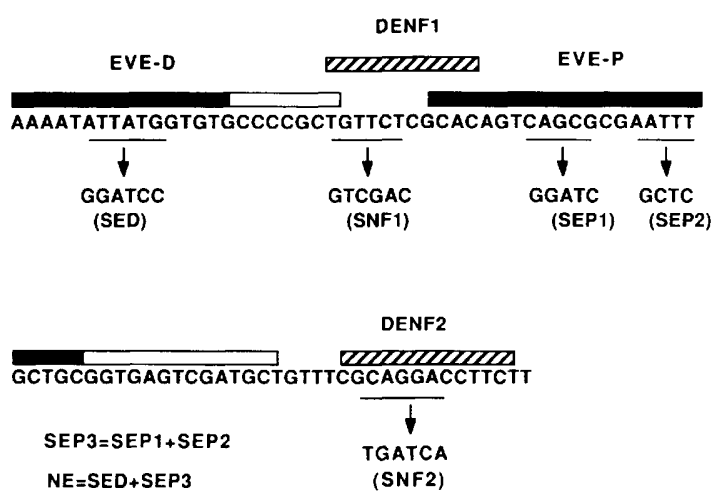

Figure 6. Summary of base substitutions in the autoregulatory element. The sequence shown here corresponds to an 85-bp region of the MAS, which contains the EVE-D-, EVE-P-, DENF1-, and DENF2-binding sites. The limits of these sites are indicated by the bars above the sequence. The filled regions of the EVE-D and EVE-P bars indicate high-affinity binding sites; the open regions denote low-affinity sites, which are protected only by high concentrations of the eve protein. Clusters of base substitutions were made using mutagenic oligonucleotides. The mutagenized sequence is indicated by the arrows. In some cases, double or even triple mutants were prepared. For example, the SEP3 mutant corresponds to the sum of the SEP1 and SEP2 mutations. NE is a triple mutant, which contains the SED mutation in EVE-D plus the SEP1 and SEP2 mutations in the EVE-P region. Two copies of the 200-bp fragment containing these various mutations were inserted in the HZ50 expression vector, and their in vivo activities were analyzed in P-transformed embryos.

tant role in transducing short-lived signals into stable patterns of gene expression during development (Meinhardt and Gierer 1980; Meinhardt 1986). Autoregulatory processes have been implicated in the expression of a number of patterning genes in Drosophila, including the gap gene Krüppel $\mid K r)$ (Warrior and Levine 1990), the pairrule genes eve (Frasch et al. 1988; Goto et al. 1989; Harding et al. 1989) and ftz (Hiromi and Gehring 1987; Pick et al. 1900), and the homeotic selector genes Deformed (Dfd) (Kuziora and McGinnis 1988) and Ultrabithorax (Ubx) (Muller et al. 1989). The type of autoregulation exhibited by $D f d$ could be distinct from that observed for segmentation genes since it is stably expressed throughout embryogenesis and larval development (Chadwick and McGinnis 1987). In contrast, segmentation genes such as $K r, \mathrm{ftz}$, and eve are transiently expressed in the early embryo, and in these cases autoregulation is thought to be important for refining and maintaining expression during brief, critical periods of development. Despite the apparent differences between $D f d$ autoregulation and the type represented by eve, in both cases the situation is probably more complex than simple autofeedback of the encoded protein with an autoregulatory element. There is evidence that both the Dfd and eve proteins act in concert with other spatially restricted factors to effect autoregulation (Frasch et al. 1988; Jack et al 1988).

The refinement of the eve stripes might involve coop- erative interactions among multiple, functionally equivalent sequences in the distal eve promoter. We have shown that multimers of short autoregulatory elements (200 or $100 \mathrm{bp}$ ) from the eve promoter are strongly activated by the eve protein. There is a dramatic increase in reporter gene expression as the 200-bp element is multimerized from one to two to four copies. Such cooperative interactions of the eve protein with distal promoter sequences could help generate a nonlinear response, causing the transition of a smooth gradient (early stripe) into a refined stripe with a sharp anterior border. This type of mechanism has been demonstrated for the activation of the gap gene hunchback $(h b)$ by the bicoid (bcd) morphogen (Struhl et al. 1989; Driever et al. 1989). At least two types of cooperativity can be envisioned, including cooperative binding to DNA and/or cooperative interactions of the eve protein with general transcription factors active in proximal regions of the promoter (e.g., Lin et al. 1990). We favor the latter mechanism since there is no indication that the eve protein binds cooperatively to the EVE-D and EVE-P regions of the autoregulatory element. For example, mutations in EVE-D do not reduce binding to EVE-P, and vice versa (see Fig. 7B,D).

\section{Identification of bona fide eve recognition sequences}

Previous in vitro binding studies have led to the identification of numerous eve recognition sequences in several promoters, including eve (Hoey et al. 1988), en (Hoey and Levine 1988), Ubx (Biggin and Tjian 1989), and Dfd (M. Regulski and B. McGinnis, pers. comm.). Several of these sites were shown to mediate repression by eve in either transient cotransfection assays (Han et al. 1989) or in vitro transcription experiments (Biggin and Tiian 1989). However, in no case were any of the binding sites shown to mediate an authentic genetic interaction in the embryo. Here, we have identified eve-binding sites that are critical for function in vivo. These eve sites function redundantly since removal of the high-affinity sites in either EVE-D or EVE-P had little or no effect on expression. However, in vivo activity was severely reduced when both regions of binding were mutated. The simplest interpretation of these results is that the eve protein directly interacts with the EVE-D and/or EVE-P regions, although we cannot rule out the possibility that eve regulates the expression of an unknown intermediate regulatory factor which, in turn, binds to the eve autoregulatory element.

It is not clear why certain $e v e$-binding sites are regulated by the eve protein in vivo while others are not. For example, high-affinity eve-binding sites in the en promoter fail to direct reporter gene expression in response to the endogenous eve protein in P-transformed embryos (Vincent et al. 1990; R. Warrior and K. Han, pers. comm.). Comparative footprint assays indicate that the eve protein has two- to fourfold higher affinity for these sites than those identified in the eve autoregulatory element (J. Jiang and T. Hoey, unpubl.). There are several 


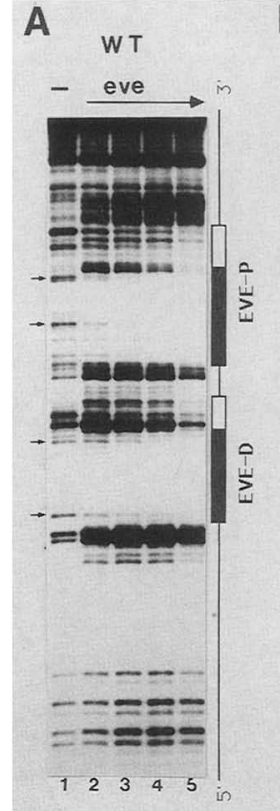

B

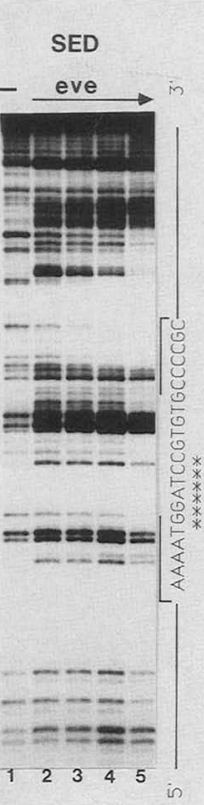

E

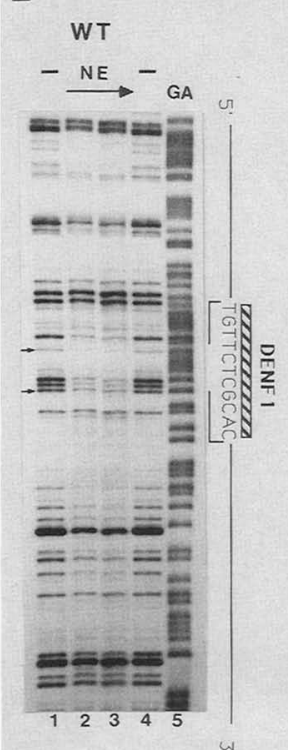

\section{C}

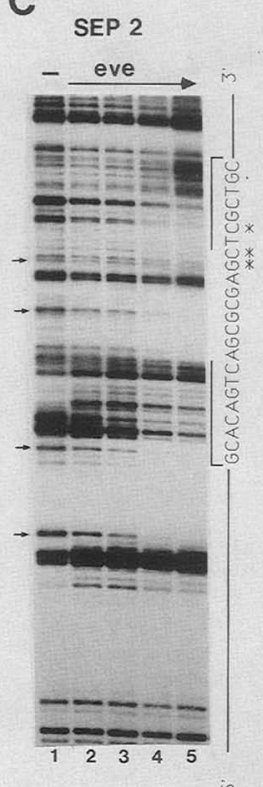

D
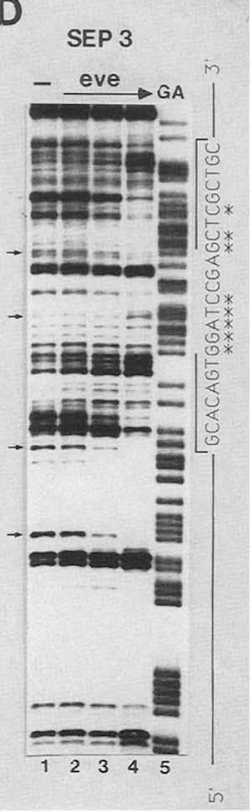

F

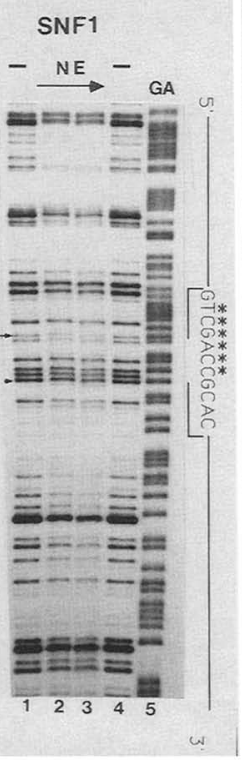

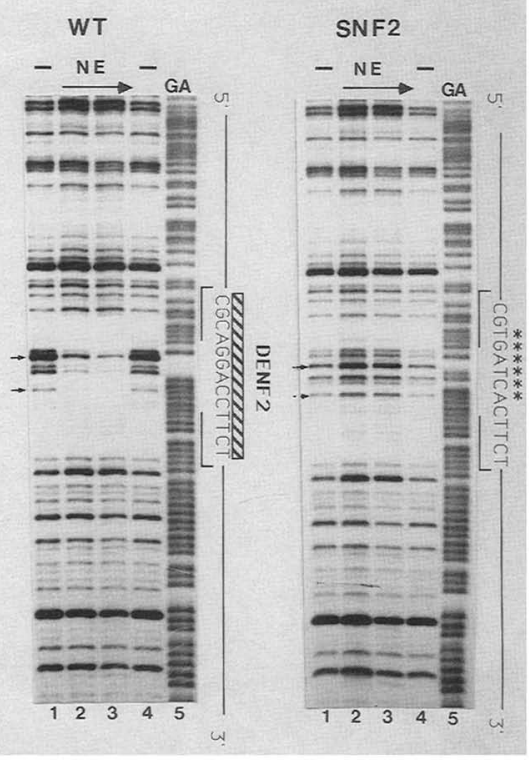

Figure 7. Base substitutions in the EVE-D, EVE-P, DENF1, and DENF2 sites disrupt DNA binding. DNase I footprint assays were done with the mutagenized DNA templates shown in Fig. 6. $(A-D)$ Bacterial extracts containing a full-length $e v e$ protein were used in these assays, along with the appropriate 200-bp DNA fragment, ${ }^{32} \mathrm{P}$-labeled on the $5^{\prime}$ end. For $A, B$, and $C$, lanes 2-5 contain progressive twofold increases in the amount of eve protein. The gel shown in $D$ contains fourfold increases in the amount of protein in lanes 2-4, and lane 5 shows the $G+A$ sequence of the DNA fragment. In all cases, lane 1 is a negative control, lacking added $e v e$ protein. $(A)$ The wild-type 200-bp fragment. The arrows at left indicate fragments that are protected by increasing amounts of the eve protein. The same bands are indicated by the arrows in the other panels, which show footprint assays with mutagenized templates. $(B)$ The SED mutation, which changes the core ATTA sequence in the EVE-D region. At least two to four times more eve protein is needed to protect the bands indicated by the two arrows as compared with the wildtype template shown in $A$. The diagram at right shows the location of the mutagenized sequence (indicated by asterisks). Despite this reduced binding to EVE-D, there is no effect on the filling of the EVE-P region. $(C)$ The SEP2 mutation, which changes sequences within the core "octamer-like" motif in a high-affinity region of EVE-P. This mutation causes a narrowing in the limits of protection obtained with eve protein. The top-most arrow indicates a doublet of bands adjacent to the mutagenized sequences, which were not protected even by the highest levels of eve protein that were used. In contrast, these bands are protected by even lower levels of eve protein in the wild-type and SED (EVE-D mutant) templates (see $A$ and $B$ ). However, this mutation has little or no effect on binding to the region indicated by the second arrow from the top. $(D)$ The SEP3 mutant, which contains substitutions in two different high-affinity regions of EVE-P. Even the highest concentrations of eve protein (lane 4) give little or no protection of the regions indicated by the top two arrows. However, binding to the low-affinity sequence just "above" the top-most arrow is still observed. Furthermore, despite the loss of binding to the high-affinity sites in EVE-P, binding of the eve protein to EVE-D appears normal. These results suggest that the $e v e$ protein does not bind to the autoregulatory element in a cooperative manner. $(E)$ Wild-type (left) and mutagenized (right) DNA templates from the 200-bp autoregulatory region were used for DNase I protection assays. The DNA fragments were ${ }^{32} \mathrm{P}$-labeled on the noncoding strand at the $3^{\prime}$ end. Increasing amounts of nuclear extract from 0- to 4-hr embryos were used in lanes 2 and 3 . The sequences to the right of the autoradiograms indicate the sites that were mutagenized in the DENF1 site (*). The small arrows (left) indicate bands within the DENF1 site. These bands are protected by at least a factor of 3 to 4 in the wild-type template but are barely changed with even high concentrations of nuclear extract in the mutagenized template. The - lanes show the DNase I pattern without added protein; GA lanes shows the $G+$ A sequence of the fragment. $(F)$ Wild-type (left) and mutagenized (right) templates that were incubated with increasing amounts of nuclear extract from 4- to 10 -hr embryos. The fragments were ${ }^{32} \mathrm{P}$-labeled on the noncoding strand at the $3^{\prime}$ end. The sequences to the right of the autoradiograms indicate the base substitutions within the DENF2 site. The arrows identify bands that reside within the DENF2 site. The SNF2 mutation in the DENF2 site completely abolishes DNA binding.

possible explanations to account for discrepancies between the efficiency of binding in vitro and activity in vivo. Perhaps eve is a very weak transcriptional activa- tor, and only clusters of binding sites in exactly the correct orientation relative to the basal promoter work in vivo. Some support for this possibility comes from the 

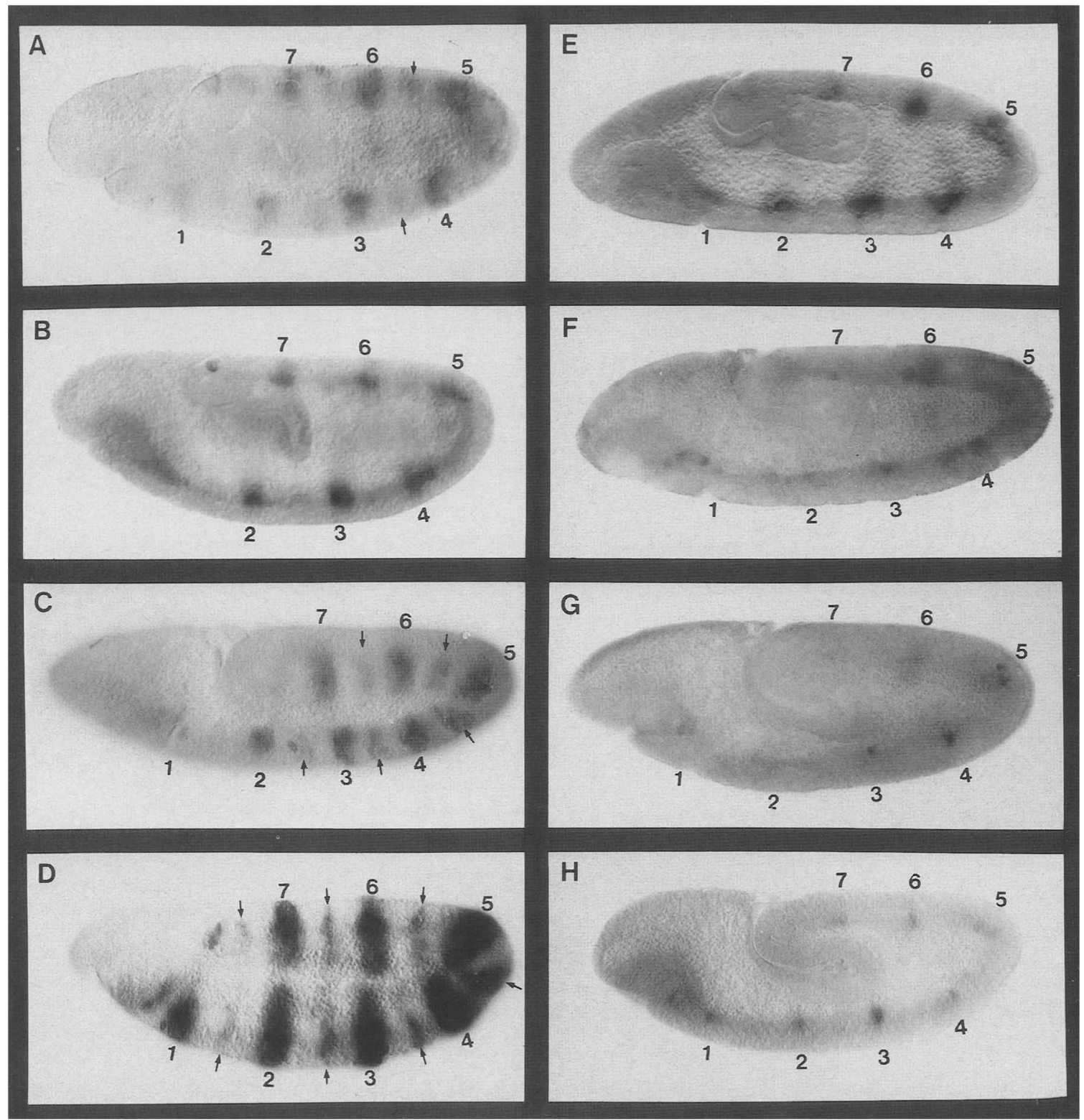

Figure 8. Effects of point mutations on in vivo expression. Embryos were collected from $P$ transformants and stained with anti- $\beta$-galactosidase antibodies, and are oriented with anterior to the left and dorsal up. The numbers refer to eve expression stripes; the arrows indicate expression in interstripe regions. $(A)$ Wild-type control, showing the staining pattern obtained with two copies of the normal 200-bp autoregulatory element. (B) The HZ2SEP1 promoter, which contains two copies of the SEP1 mutation in EVE-P. This mutation has little or no effect on expression. $(C)$ The HZ2SEP2 promoter, which contains two copies of the SEP2 mutation (in the octamer-like element) in EVE-P. This mutation has no effect on the seven stripes of expression but causes an increase in interstripe expression. (D) The HZ4SEP2 promoter, which contains four copies of the SEP2 template. The seven stripes are strong and sharp, but there is a substantial elevation in the levels of interstripe expression. (E) The HZ2SED promoter, which contains two copies of the SED mutation in EVE-D. There is at most only a slight reduction in expression. $(F)$ The HZ2NE promoter, which contains two copies of a triple mutant that impairs binding to EVE-D and the two high-affinity sites within EVE-P. There is a severe reduction in expression. $(G)$ The HZ2SNF1 promoter, which contains two copies of the SNFl mutation in the DENF1 site. There is a severe reduction in expression. $(H)$ The HZ2SNF2 promoter, which contains two copies of the SNF2 mutation in the DENF2 site. There is a significant reduction in expression.

orientation dependence of eve autoregulatory sequences (see Figs. 1 and 2). Alternatively, it is conceivable that eve must act in concert with other factors bound to neighboring sites to function as a transcriptional activa- tor. According to this "lock and key" model, a functional eve response element must contain a proper arrangement of binding sites both for the eve protein and neighboring cofactors (summarized in Fig. 9). 

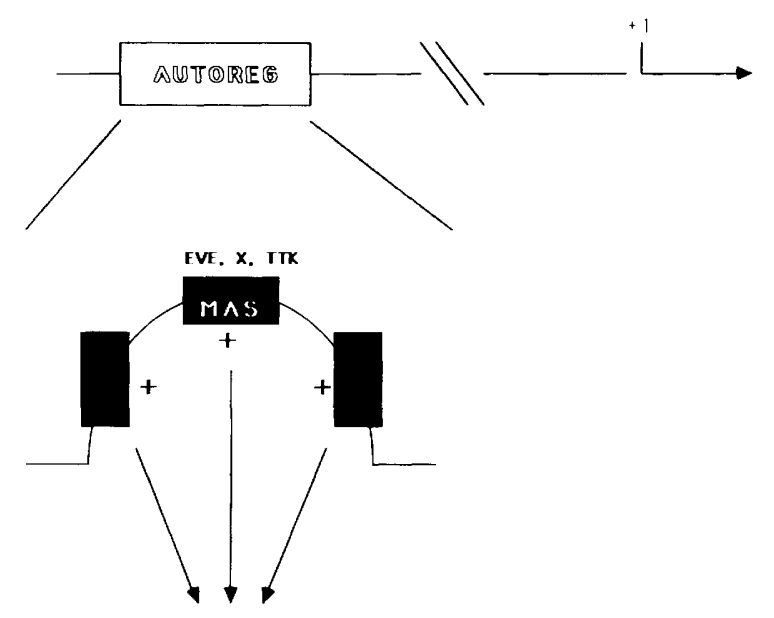

$++t$

Figure 9. Summary of cooperative and combinatorial interactions underlying eve autoregulation. The top line represents the eve promoter; the autoregulatory element is located between -5.9 and $-5.2 \mathrm{~kb}$ upstream from the transcription start site. We have presented evidence that this element might be composed of multiple copies of a 100-bp MAS, which is represented by the solid rectangle. Each copy of the MAS contains binding sites for eve, DENF1, and DENF2. It is possible that DENF2 corresponds to $t k$. The third factor is denoted $X$ and might correspond to the GAGA protein. Combinatorial interactions among these three proteins are responsible for each MAS mediating weak activation in response to the eve protein. Full activation depends on cooperative interactions among multiple MAS elements.

\section{Combinatorial interactions between eve and nuclear factors}

At least three proteins, eve, DENF1, and DENF2, are essential for eve autoregulation. DENF1 and DENF2 probably represent different proteins since their binding sites are totally distinct (see sequence, Fig. 4A). Mutations that reduce binding of any one of these factors cause a severe reduction or loss in in vivo activity. This catastrophic loss in expression suggests that eve, DENF1, and DENF2 act combinatorially to activate eve transcription. If the proteins were functioning in an additive manner, then the removal of any one binding site should cause a relatively mild reduction in expression. There are at least two types of models to account for combinatorial interactions among these proteins. First, interactions might permit cooperative binding of the eve protein to DNA. eve alone does not bind with very high affinity to the autoregulatory element, and perhaps it is targeted to these sites by appropriate protein-protein interactions with the neighboring DENF1 and DENF2 proteins. This mechanism has been demonstrated in the yeast mating-type system, where the binding of the homeo box protein $\alpha 2$ to $\alpha$-specific promoters depends on cooperative interactions with the general transcription factor MCM1 (Keleher et al. 1988). A nonexclusive alternative is that protein-protein interactions might cause conformational changes in the eve, DENF1, or DENF2 proteins, which unmasks their activation domains. Perhaps these proteins fail to function as effective transcriptional activators when in isolation.

To sort out the exact mechanism underlying combinatorial interactions among these proteins, it will be neccessary to clone and characterize the DENF1 and DENF2 factors. It is possible that DENF2 corresponds to a zinc finger protein called $t t k$, which is expressed in early embryos (Harrison and Travers 1990). DENF1 contains some sequence similarities with the binding sites for a general factor called GAGA (Biggin and Tjian 1988; Soeller et al. 1988), which binds to a number of different promoters expressed in early embryos, including $U b x$ and $e n$.

\section{Materials and methods}

Construction of eve/hsp70 heterologous promoters

The starting plasmid (pBlu $1 \mathrm{E}$ ) for most of our studies corresponds to a 200-bp SmaI-PstI DNA fragment from a distal region of the eve promoter, between -5.4 and $-5.2 \mathrm{~kb}$ upstream from the transcription start site, inserted into the pBluescript vector (Strategene, La Jolla, CA). Previous studies have shown that this fragment is sufficient to drive weak autoregulatory activity (Harding et al. 1989). Multimerization, deletion, and base substitutions within this fragment were all done in the pBluescript vector, and the derivatives were then excised with $X b a I-K p n I$ and inserted into the HZ50 P-transformation vector (Hiromi and Gehring 1987). To construct a heterologous promoter containing two copies of the 200-bp fragment, we inserted a 200-bp EcoRI fragment into the pBlu $1 \mathrm{E}$ vector, which already contained one copy of the fragment. There is a native EcoRI site located 13 bp downstream from the SmaI site in the eve sequences, and the second EcoRI site is derived from the polylinker of the vector. The EcoRI fragment was blunted by filling in the ends with Klenow and cloned into the SmaI site of the pBlu $1 E$ vector. Plasmids were selected that contained two tandem copies of fragment and were removed from the vector in a single fragment using $X b a I-K p n I$. This 400 -bp fragment was fused into the HZ50 vector to obtain the HZ2E00 construct (see Fig. 1). The four-copy promoters were prepared by ligating the 200-bp EcoRI into the unique EcoRI site of the pBluescript vector. A high ratio of insert to vector was used, and recombinant plasmids were screened for those that contain four tandem repreats. In general, we found that there was a selection against recombinants containing the fragment in "head-to-head" orientations. Tandem repeats in either orientation relative to the transcription start site were inserted separately into the HZ50 vector.

In vitro mutagenesis was done to create four separate $B c$ II sites along the length of the 200-bp EcoRI fragment (see below). Templates containing individual and almost all pairwise combinations of these sites were used to create specific truncations and internal deletions within the 200-bp autoregulatory fragment. For example, to delete the EVE-P region, a 200-bp fragment containing only the BclI sites 2 and 3 was used /see map, Fig. 4). A pBluescript recombinant plasmid containing this template was digested with $B c$ II (there are no such sites in the vector) and religated. The internally deleted DNA fragment was excised from the vector with SmaI-PstI, filled in with T4 polymerase, and ligated into the unique SmaI site of the pBluescript recombinant containing one copy of the corresponding truncated fragment. To obtain four copies of the $\Delta 23$ fragment, we removed the two-copy insert with $\mathrm{XbaI}-E c o \mathrm{RV}$ and ligated it 
into the $X b a I-S m a I$ sites in a pBlucscript plasmid already containing two copies of the $\Delta 23$ fragment.

To create terminal truncations within the 200-bp fragment, templates were used that contain either the BclI site 1 or 4 . For deletion of the $5^{\prime}$ region of the 200-bp fragment, a plasmid containing an insert with $B c$ II 1 was digested with a BclI-BamHI fragment la BamHI site is located 6 bp upstream from the SmaI site within the polylinker). After digestion, the plasmid was religated, and the fragment was removed from the vector using $X b a I$ and $E c o R V$. The $X b a I$ site was filled in with Klenow, and the fragment was cloned into the unique EcoRV site of a pBluescript recombinant already containing the deleted 200-bp fragment lacking sequences between the BamHI and $B c l I 1$ sites. To remove $3^{\prime}$ sequences from the 200-bp autroegulatory fragment, a template was used containing $B c l$ site 4 . A recombinant plasmid containing this template was digested with $\mathrm{XbaI}-\mathrm{BclI}$, and this truncated fragment (lacking sequences $3^{\prime}$ to the $B c$ II site 4 ) was inserted into pBluescript cut with $\mathrm{XbaI}$ and BamHI. The truncated fragment was removed from the recombinant plasmid by digesting with EcoRV and BamHI. The BamHI site was filled-in with Klenow and the fragment was inserted into the unique $E c o R V$ site of a plasmid that already contained one copy of the truncated fragment.

\section{Site-directed mutagenesis}

Base substitutions in the binding sites were made with appropriate mutagenic oligonucleotides using the "muta-gene" kit purchased from Bio-Rad (Richmond, CA). Mutagenic oligonucleotides contained $9-10$ bases of flanking sequence on either side of the mutagenized sequence. Mutations were made that created restriction sites to facilitate screening. For example, the mutagenic oligonucleotide GACTGTGCGGTCGACGCGGGGCAC was used to disrupt the DENF1-binding site. The base substitutions are underlined and correspond to a Sall restriction site. Mutagenesis was done essentially as described in the instructions that came with the kit, except that single-stranded DNA templates were made directly from the pBluescript vector. After annealing the mutagenic oligonucleotide with the singlestranded template, polymerization was driven by T4 DNA polymerase and terminated by ligation with $\mathrm{T} 4$ ligase. The doublestranded templates were transformed into the DH5 strain of $E$. coli, and mutant templates were identified by screening minipreparations of DNA for the restriction sites created by mutagenesis. In all cases, the identities of mutant templates were confirmed by DNA sequencing. For some of the templates, we created double mutants by using two different mutagenic oligonucleotides in the same polymerization reaction. For example, the triple mutant NE, which disrupts the EVE-D region and two binding sites within the EVE-P region, was made by annealing two different mutagenic oligonucleotides at the same time. One of the oligonucleotides generated the SED 1 substitutions in EVE-D, whereas the other created both the SEP1 and SEP2 substitutions in EVE-P (see Fig. 6).

\section{P-element transformations and antibody staining}

Heterologous fusion promoters were introduced into the Drosophila germ line via P-element-mediated transformation, as described by Rubin and Spradling (1982). The rosy ${ }^{506}$ line was used for all injections.

The expression patterns of the $l a c Z$ reporter gene were examined by staining whole-mount embryos with a $1: 1000$ dilution of a rabbit anti- $\beta$-galactosidase antibody (purchased from Organon Teknika, West Chester, PA). Histochemical staining was done with the Elite $\mathrm{ABC}$ kit from Vector Labs (Burlingame, $\mathrm{CA}$ ) using biotinylated anti-rabbit immunoglobulin antibodies and horseradish peroxidase conjugated to streptavidin.

\section{Prepartion of bacterial eve protein and embryo nuclear extracts}

The eve protein was overexpressed in bacteria using the T7 promoter, exactly as described by Hoey et al. (1988). After induction, bacterial extracts were prepared in guanidine- $\mathrm{HCl}$ and renatured by dialysis as described by Hoey and Levine (1988).

Embryos were collected at $25^{\circ} \mathrm{C}$ from population cages of the Oregon-R strain and aged to give distributions of either $0-4$ or 5-10 hr. To accumulate large amounts of material for extraction, staged embryos were kept at $4^{\circ} \mathrm{C}$ for as long as 3 days. Similarly aged embryos were pooled, dechorionated in sodium hypochlorite, and washed first in $\mathrm{NaCl} /$ Triton $\mathrm{X}-100$ and finally in water. Nuclear extracts were prepared essentially as described previously (Biggin and Tjian 1988; Soeller et al. 1988). We found that nuclear extracts from 5- to 10-hr embryos contained higher DENF2-binding activity than extracts from 0- to 4-hr embryos. DENF1 activity is quite weak in 5- to 10 -hr extracts and is somewhat higher in $0-$ to $4-\mathrm{hr}$ extracts. Extracts prepared from 0- to 4-hr embryos were used directly for DNA binding, while 5- to 10 -hr extracts were first fractionated in a heparin-agarose column, as described by Heberlein et al. (1985).

\section{DNA-binding assays}

DNase I footprint assays were done essentially as described previously (Heberlein et al. 1985; Hoey et al. 1988). Binding reactions were done with $\sim 5 \mathrm{ng}$ of ${ }^{32} \mathrm{P}$-labeled DNA in $50 \mu \mathrm{l}$ of a buffer containing $110 \mathrm{mM} \mathrm{KCl}, 47.5 \mathrm{mM}$ HEPES (pH 7.9), 13.75 $\mathrm{mM} \mathrm{MgCl} 2,1 \mathrm{mM} \mathrm{DTT}, 17 \%$ glycerol, and $0.05 \%$ NP-40. After incubating for $60 \mathrm{~min}$ on ice, $50 \mu \mathrm{l}$ of $10 \mathrm{mM} \mathrm{MgCl}_{2}$ and $5 \mathrm{mM}$ $\mathrm{CaCl}_{2}$ was added to the reaction, followed by freshly diluted DNase I (purchased from Worthington). Binding reactions were done with the bacterial eve protein including $1 \mu \mathrm{g}$ of poly[d(I-C)] as carrier, and the DNase I digestion was done for 2-3 min on ice using a final concentration of $0.4 \mu \mathrm{g} / \mathrm{ml}$. Binding reactions with nuclear extracts contained $0.5 \mu \mathrm{g}$ of poly[d(I-C)] and a total of $\sim 50 \mu \mathrm{g}$ of total protein extract. Because the crude extract contains a high level of exonuclease activity, $\mathrm{MgCl}_{2}$ was omitted from the binding buffer. DNase I digestions were done with 10 -fold more DNase I (than for the eve reactions), and digestions were done at room temperature for $1 \mathrm{~min}$. DNase I reactions were stopped by adding $90 \mu \mathrm{l}$ of $1 \%$ SDS, $20 \mathrm{~mm}$ EDTA, $200 \mathrm{~mm}$ $\mathrm{KCl}, 250 \mu \mathrm{g} / \mathrm{ml}$ of yeast tRNA. The samples were extracted twice with phenol-chloroform (1:1), ethanol-precipitated, and electrophoresed in $8 \%$ polyacrylamide- $7.5 \mathrm{M}$ urea gels. The DNA fragments used for footprinting were prepared by labeling with $\left[\gamma^{32} \mathrm{P}\right] \mathrm{ATP}$ and polynucleotide kinase, and were isolated from native polyacrylamide gels.

\section{Acknowledgments}

We thank Tony Ip and Doug Read for help in preparing the nuclear extracts, and Dusan Stanojevic for advice on the footprint assays. We are grateful to Rachel Kraut for guidance on $P$ transformation. We also thank Doug Read and James Manley for providing a sample of the $t t k$ - $\beta$-galactosidase fusion protein. This work was supported by a grant from the National Institute of Health (GM37971).

The publication costs of this article were defrayed in part by payment of page charges. This article must therefore be hereby marked "advertisement" in accordance with 18 USC section 1734 solely to indicate this fact. 


\section{References}

Akam, M. 1987. The molecular basis for metameric pattern in the Drosophila embryo. Development 101: 1-22.

Biggin, M.D. and R. Tjian. 1988. Transcription factors that activate the Ultrabithorax promoter in developmentally staged extracts. Cell 53: 699-711.

— 1989. A purified Drosophila homeodomain protein represses transcription in vitro. Cell 58: 433-440.

Chadwick, R. and W. McGinnis. 1987. Temporal and spatial distribution of transcripts from the Deformed gene of Drosophila. EMBO I. 6: 779-789.

Driever, W., G. Thoma, and C. Nüsslein-Volhard. 1989. Determination of spatial domains of zygotic gene expression in the Drosophila embryo by the affinity of binding sites for the bicoid morphogen. Nature 340: 363-367.

Frasch, M. and Levine, M. 1987. Complementary patterns of even-skipped and fushi tarazu expression involve their differential regulation by a common set of segmentation genes in Drosophila. Genes \&) Dev. 1: 981-995.

Frasch, M., T. Hoey, C. Rushlow, H. Doyle, and M. Levine. 1987. Characterization and localization of the even-skipped protein of Drosophila. EMBO 1. 6: 749-759.

Frasch, M., R. Warrior, J. Tugwood, and M. Levine. 1988. Molecular analysis of even-skipped mutants in Drosophila development. Genes \&) Dev. 2: 1824-1838.

Goto, T., P. Macdonald, and T. Maniatis. 1989. Early and late periodic patterns of even-skipped expression are controlled by distinct regulatory elements that respond to different spatial cues. Cell 57: 413-422.

Han, K., M. Levine, and J.L. Manley. 1989. Synergistic activation and repression of transcription by Drosophila homeo box proteins. Cell 56: 573-583.

Harding, K., C. Rushlow, H.J. Doyle, T. Hoey, and M. Levine. 1986. Cross-regulatory interactions among pair-rule genes in Drosophila. Science 233: 953-959.

Harding, K., T. Hoey, R. Warrior, and M. Levine. 1989. Autoregulatory and gap response elements of the even-skipped promoter of Drosophila. EMBO J. 8: 1205-1212.

Harrison, S.D. and A. Travers. 1990. The tramtrack gene in Drosophila encodes a zinc finger protein that interacts with the $f t z$ transcriptional regulatory region and shows a novel embryonic expression pattern. EMBO /. 9: 207-216.

Heberlein, U., B. England, and R. Tjian. 1985. Characterization of Drosophila transcription factors that activate the tandem promoters of the alcohol dehydrogenase gene. Cell 41: 956977.

Hiromi, Y. and W.J. Gehring. 1987. Regulation and function of the Drosophila segmentation gene fushi tarazu. Cell 50: $963-974$.

Hoey, T. and M. Levine. 1988. Divergent homeo box proteins recognize similar sequences in Drosophila. Nature 332858 861.

Hoey T., R. Warrior, J. Manak, and M. Levine. 1988. The DNA binding activities of the Drosophila even-skipped protein are mediated by its homeo domain and influenced by protein context. Mol. Cell. Biol. 8: 4598-4607.

Ingham, P.W. 1988. The molecular genetics of embryonic pattern formation in Drosophila. Nature 335: 25-34.

Ingham, P.W., N.E. Baker, and A. Martinez-Arias. 1988. Regulation of segment polarity genes in the Drosophila blastoderm by fushi tarazu and even-skipped. Nature 331: 73-75.

Jack, T., M. Regulski, and W. McGinnis. 1988. Pair-rule segmentation genes regulate the expression of the homeotic selector gene, Deformed. Genes \&) Dev. 2: 635-643.

Keleher, C.A., C. Goutte, and Johnson, A.D. 1988. The yeast cell-type- specific repressor alpha2 acts cooperatively with a non-cell-type-specific protein. Cell 53: 927-936.

Kuziora, M. and W. McGinnis. 1988. Autoregulation of a Drosophila homeotic selector gene. Cell 55: 477-485.

Lawrence, P.A. and P. Johnston. 1989. Pattern formation in the Drosophila embryo: Allocation of cells to parasegments by even-skipped and fushi tarazu. Development 105: 761-767.

Lawrence, P.A., P. Johnston, P. Macdonald, and G. Struhl. 1987. Borders of parasegments in Drosophila embryos are delimited by the fushi tarazu and even-skipped genes. Nature 328: $440-442$.

Levine, M. and T. Hoey. 1988. Homeo box proteins as sequencespecific transcription factors. Cell 55: 537-540.

Lin, Y.-S., M. Carey, M. Ptashne, and M.R. Green. 1990. How different eukaryotic transcriptional activators can cooperate promiscuously. Nature 345: 359-361.

Macdonald, P.M., P. Ingham, and G. Struhl. 1986. Isolation, structure, and expression of even-skipped: A second pairrule gene of Drosophila containing a homeo box. Cell 47: 721-734.

Meinhardt, H. 1986. Hierarchical inductions of cell states: A model for segmentation in Drosophila. I. Cell Sci. (suppl.) 4: $357-381$.

Meinhardt, H. and A. Gierer. 1980. Generation and regeneration of sequences of structures during morphogenesis. $/$. Theor. Biol. 85: 429-450.

Muller, J., F. Thuringer, M. Biggin, B. Zust, and M. Bienz. 1989. Coordinate action of a proximal homeoprotein binding site and a distal sequence confers the Ultrabithorax expression pattern in the visceral mesoderm. EMBO /. 8: 4143-4151.

Nüsslein-Volhard, C. and E. Wieschaus. 1980. Mutations affecting segment number and polarity in Drosophila. Nature 287: 795-801.

Nüsslein-Volhard, C., H. Kluding, and G. Jürgens. 1985. Genes affecting the segmental subdivsion of the Drosophila embryo. Cold Spring Harbor Symp. Quant. Biol. 50: 145-154.

Pick, L., A. Schier, M. Affolter, T. Schmidt-Glenewinkel, and W.J. Gehring. 1990. Analysis of the $f t z$ upstream element: Germ layer-specific enhancers are independently autoregulated. Genes \&) Dev. 4: 1224-1239.

Read, D., T. Nishigaki, and J.L. Manley. 1990. The Drosophila even-skipped promoter contains multiple, overlapping factor binding sites and is transcribed in a stage-specific manner in vitro. Mol. Cell. Biol. 10: 4334-4344.

Rubin, G.M. and A.C. Spradling. 1982. Genetic transformation of Drosophila with transposable element vectors. Science 218: 348-353.

Soeller, W.C., S.J. Poole, and T. Kornberg. 1988. In vitro transcription of the Drosophila engrailed gene. Genes $\Leftrightarrow$ Dev. 2: 68-79.

Stanojevic, D., T. Hoey, and M. Levine. 1989. Sequence-specific DNA binding activities of the gap proteins encoded by hunchback and Kruppel in Drosophila. Nature 341: 331335.

Struhl, G., K. Struhl, and P.M. Macdonald. 1989. The gradient morphogen bicoid is a concentration-dependent transcriptional activator. Cell 57: 1259-1273.

Vincent, J.-P., J.A. Kassis, and P.J. O'Farrell. 1990. A synthetic homeodomain binding site acts as a cell type specific, promoter specific enhancer in Drosophila embryos. EMBO /. 9: 2573-2578.

Warrior, R. and M. Levine. 1990. Dose-dependent regulation of pair-rule stripes by gap proteins and the initiation of segment polarity in Drosophila. Development 110: 759-770. 


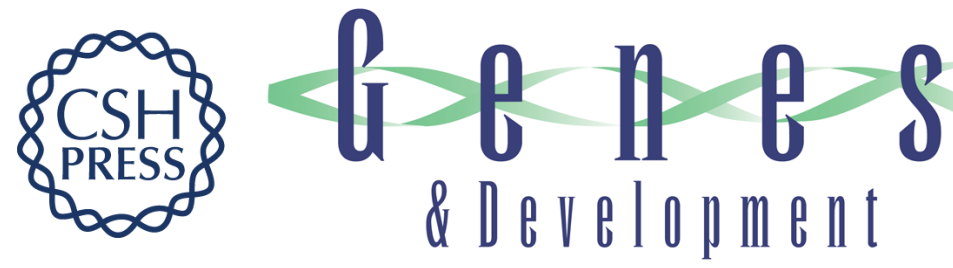

\section{Autoregulation of a segmentation gene in Drosophila: combinatorial interaction of the even-skipped homeo box protein with a distal enhancer element.}

$\mathrm{J}$ Jiang, T Hoey and M Levine

Genes Dev. 1991, 5:

Access the most recent version at doi:10.1101/gad.5.2.265

References This article cites 40 articles, 12 of which can be accessed free at: http://genesdev.cshlp.org/content/5/2/265.full.html\#ref-list-1

License

Email Alerting Receive free email alerts when new articles cite this article - sign up in the box at the top Service right corner of the article or click here.

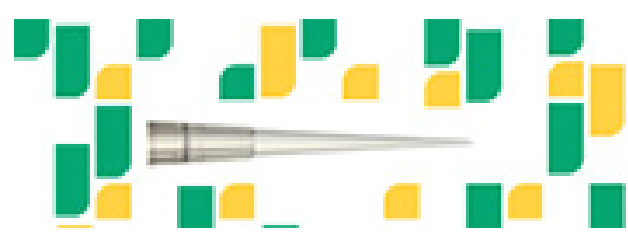

Focused on your science. 